
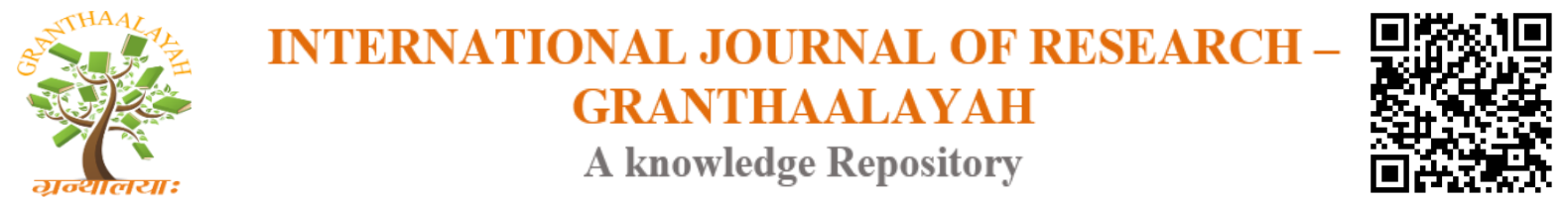

Science

\title{
HYBRID GRIDS ANALYSIS WITH RENEWABLE ENERGY AND THERMAL ENERGY FOR STREET LIGHT -A CASE STUDY
}

\author{
Rajeev Ranjan ${ }^{* 1}$, Mahesh kr Nagar ${ }^{2}$, M.Nithin Choudary ${ }^{3}$, M.K.Paswan ${ }^{4}$, Manish kumar $^{5}$ \\ ${ }_{* 1,2,3,4,5}$ Mechanical Engineering Department, NIT Jamshedpur, Jamshedpur-831014, India
}

\begin{abstract}
This paper presents a techno-economic assessment for a unique Isolated Hybrid Power System (IHPS) design which could be used for remote areas isolated from the grid which also has the capability of being operated as a smart the hybrid energy system considering solar and wind energy sources for the purpose of street lighting. Solar-Wind Street light is an intelligent, small scale, and off grid LED lighting system. The modelling design and simulations were based on Simulations conducted using the Data collected and HOMER Energy Planning and Design software tools. Its components are solar panel, wind generator system (PVC blowers), Dynamo, LDRs, battery, LED light, charge controller. The energy stored in battery during day time due to solar panel, get extracted by LEDs during the night time (because LDRs get activated due to absence of sun light). Wind also charges the batteries due to wind which is used for glowing street light. The advantage of this idea is to avoid daily running cost and make the system purely off-grid. In this prototype, we have used $12 \mathrm{~V}$ DC system to supply energy to the lights.
\end{abstract}

Keywords: Hybrid Grids; Renewable Energy; Thermal Energy; Street Light.

Cite This Article: Rajeev Ranjan, Mahesh kr Nagar, M.Nithin Choudary, M.K.Paswan, and Manish kumar. (2018). "HYBRID GRIDS ANALYSIS WITH RENEWABLE ENERGY AND THERMAL ENERGY FOR STREET LIGHT -A CASE STUDY." International Journal of Research - Granthaalayah, 6(2), 246-254. https://doi.org/10.5281/zenodo.1194671.

\section{Introduction}

Energy is one of the most important components of economic infrastructure. It is the basic input required to sustain economic growth. There is direct relation between the level of economic development and per capita energy consumption. Simply speaking more developed a country, higher is the per capita consumption of energy and vice versa. The per capita electricity consumption in India has been increasing continuously over the last decade because of the significant improvement in electrification of villages. Still, India is far behind when compared to the rest of the world. Compared to some of the developed countries of the world, the per capita electricity consumption in India is very low. India's per capita consumption is $1 / 3^{\text {rd }}$ of the world average and is just $10 \%$ of that of Australia. It is just $7.5 \%$ that of USA and $6.6 \%$ of Canada. The per capita consumption in UK also is more than 5 times that of India. There are two ways of 
electricity generation either by conventional energy resources or by non-conventional energy resources. Electricity energy demand in the world increases so as to complete demand energy is to be generated. Now a day's electrical energy is generated by conventional energy resources like coal, diesel, nuclear etc. The main drawback of these sources is that it produces waste like ash in coal power plant, nuclear waste in nuclear power plant and taking care of this wastage is very costly. Conventional energy sources include oil, gas and coal. These conventional sources are usually fossil fuels. Their use leads to increased greenhouse gas emissions and other environmental damages such as climate change. Conventional energy resources are depleting very rapidly and are unable to cop up with increasing energy demand due to increasing population growth. So there is a urgent need to find another sources of energy which should be environment friendly and cost effective. Geothermal, tidal, wind, solar etc. are such examples of renewable energy sources. Solar energy and wind energy are clean, illimitable, and environmental friendly. The energy sectors were already attracted to use renewable energy in large scale. Renewable energy sources offer an efficient solution to the global warming and high fuel cost. Therefore, there is a growing interest in RES, particularly photovoltaic (PV) and wind energy. Recently, hybrid power systems using RE are becoming most popular due to their potential advantages. Wind system cannot supply the load continuously due to their intermittent nature. As load demands are always changing with time, the changes in solar or wind energy generations do not always match with the time distribution of consumer's demand. Therefore, there is a need of additional battery storage or other components for providing continuous power supply to the load. It has been investigated that a hybrid PV/Wind/battery system is a secure source of electricity. However, due to the high cost of battery energy storage, a stand-alone system is very expensive. Therefore, it is essential to find an effective solution to this problem. On the other hand, a grid connected hybrid power system with proper planning requires storage with less capacity which, in turn, reduces the cost. The main goal of this paper is to analyze the economic feasibility of grid connected hybrid power system to meet the load requirements of NIT Jamshedpur, India.

\section{System Description}

In this paper, both on and off-grid hybrid power system models have been designed using HOMER to evaluate and determine the cost of different models. HOMER simulation software needs some input data to evaluate the optimization results for different combinations which are described in the next section. The average energy consumption of street lights of NIT, Jamshedpur is $434 \mathrm{kwh} / \mathrm{d}$. Figure 1 shows the daily average load profile in which 18:00 to 6:00 $\mathrm{h}$ time period has been found as demand period. Here $66.31 \mathrm{kw}$ is considered as peak load consumption. The scaled annual average (kwh/d) is 434 . Figure 2 shows the monthly average load. Wind Speed and Solar Radiation the data of wind speed and solar radiation is obtained from NASA surface meteorology and solar energy database. Wind speed data obtained at $50 \mathrm{~m}$ above the surface of sea level for the location of NIT, Jamshedpur as shown in Fig. 3. The figure shows that the wind speed ranges from 1.69 to $3.190 \mathrm{~m} / \mathrm{s}$. The highest wind speed occurs in May. Monthly average solar radiation data is shown in Fig. 4. As used in HOMER software, the latitude and longitude of NIT, Jamshedpur are $22.77^{\circ} \mathrm{N}, 86.14^{\circ} \mathrm{E}$, respectively. The annual average solar radiation is estimated to be $4.78 \mathrm{kWh} / \mathrm{m} 2 /$ day. 


\section{Daily Profile}

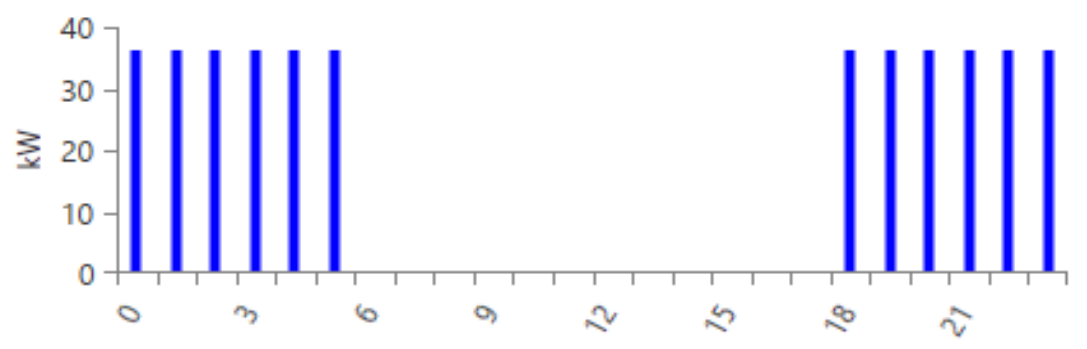

Figure 1: Load profile (daily)

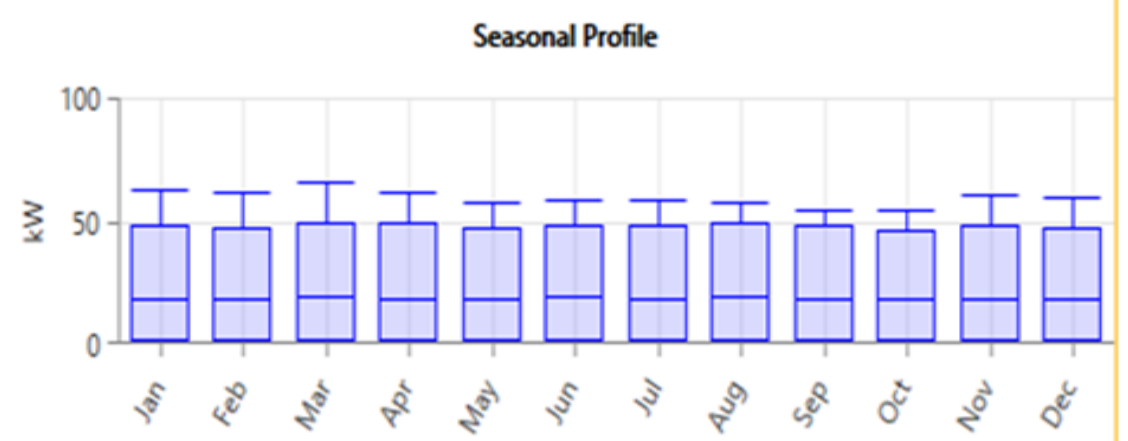

Figure 2: Load for a complete year (monthly average)

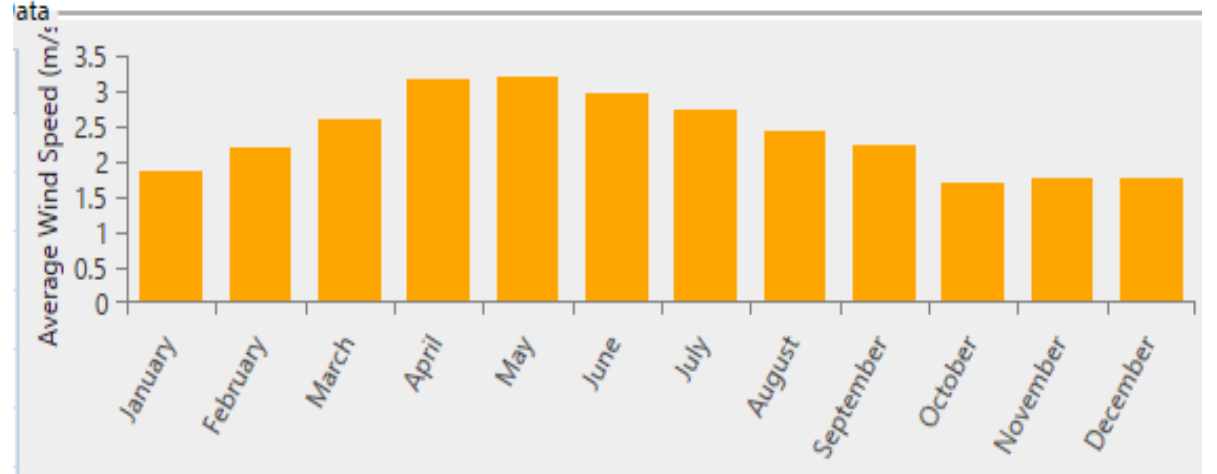

Figure 3: Wind speed (monthly average)

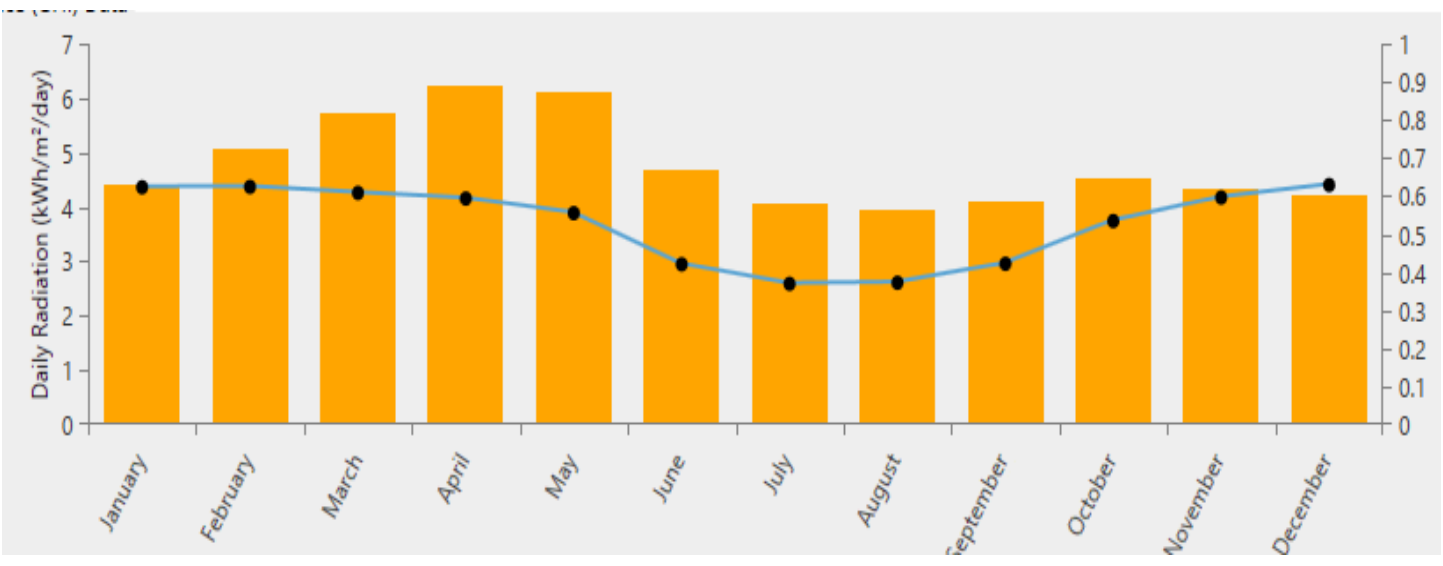

Figure 4: Solar radiation and clearness index (monthly average) 


\section{Methodology}

\subsection{Homer Software}

National Renewable Energy Laboratory (NREL) in the United States (USA) developed HOMER software. It is generally used for the design and analysis of hybrid power system. In this paper, electrical load, solar radiation and wind speed data, component details and costs are provided as input information to HOMER.

\subsection{Cost Analysis Procedure By Homer}

\section{Net Present Cost (NPC)}

NPC indicates the installation cost and the operating cost of the system throughout its lifetime which is calculated as follows:

$$
N P C=T A C / C R F\left(i, R p r_{j}\right)
$$

Where,

TAC is the total annualized cost $(\$)$.

$\mathrm{CRF}$ is the capital recovery factor

$i$ is the interest rate in percentage

and $\mathrm{Rpr}_{\mathrm{j}}$ is the project life time in year.

\section{Total Annualized Cost}

It is the sum of the annualized costs of every equipment of the power system including capital and operation and maintenance cost. It also includes replacement and fuel cost.

\section{Capital Recovery Factor}

It is a ratio which is used to calculate the present value of a series of equal annual cash flows.

$$
C R F=\frac{1-(1+i)^{n}}{(1+i)^{n_{-}}}
$$

Where, nrepresents the number of years and $i$ represents the annual real interest rate.

\section{Annual Real Interest Rate}

It is a function of the nominal interest rate shown as

$$
i=\left(i^{\prime}-F\right) /(1+F)
$$

Where,

$i$ is the real interest rate

$i^{\prime}$ is the nominal interest rate

and $F$ is the annual inflation rate. 


\section{Cost of Energy (COE)}

It is the average cost $/ \mathrm{kWh}$ ofuseful electrical energy produced by the system.

The COE is calculated as follows [12]:

$$
C O E=\frac{\text { prim }, A C}{L+L}_{\text {prim }, D C}
$$

Where,

$L_{\text {prim, } A C}$ is the AC primary load and $L_{\text {prim, } D C}$ is the DC primary load.

\section{Simulation Model}

The components are chosen from HOMER to perform simulation. Figure 5 shows the grid connected hybrid power system design using HOMER which consists of PV array, wind generator, converter, load, battery.

To estimate the system performance under different situations, HOMER simulates the above two arrangements at the same area and same load based on different costs such as the estimated installation cost, operation and maintenance cost, replacement cost, interest, cost of energy.

The main components of the grid connected hybrid system are wind turbine, PV array, battery bank, and a power converter. For economic analysis, the following values are used.

\subsection{Photovoltaic Array}

Name: Generic Flat Plate PV, manufactured by Generic.

Its efficiency is about $17.30 \%$ and lifetime about 25 years. Initial installation cost of PV arrays is assumed as $\$ 923$ per $\mathrm{kW}$ and operation and maintenance cost practically zero.

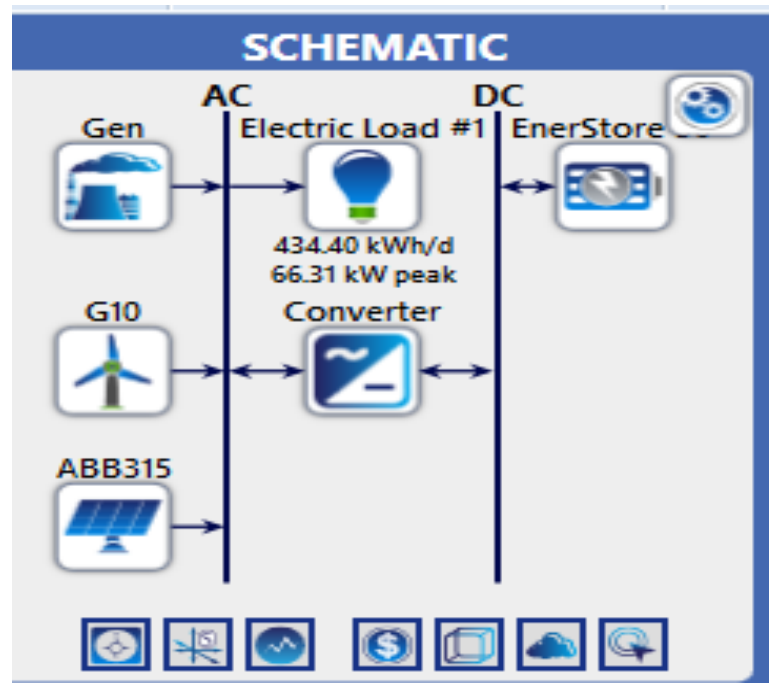

Figure 5: The arrangement of hybrid power system (off-grid) 


\subsection{Wind Turbine}

For this study, one Generic $10 \mathrm{~kW}$ wind turbine has been used. Its lifetime is about 25 years. The capital and operation and maintenance costs are $\$ 23,076$ and $\$ 10$ respectively.

\begin{tabular}{|c|c|c|c|c|c|c|c|c|c|c|c|c|c|c|c|c|c|c|}
\hline \multicolumn{2}{|c|}{ Sensitivity } & \multicolumn{5}{|c|}{ Combination of System } & \multicolumn{7}{|c|}{ Architecture } & \multicolumn{4}{|c|}{ Cost } & \\
\hline $\begin{array}{l}\text { Disel Fuel } \\
\text { Price } \\
\text { (SL) }\end{array}$ & $\mid \begin{array}{c}\text { Electrical } \\
\text { Load } \\
\mathrm{kWh} / \mathrm{day}\end{array}$ & PV & WT & $D G$ & Battery & Converter & $\mathrm{PV}(\mathrm{kW})$ & $\begin{array}{l}\text { MPPT } \\
(\mathrm{kW})\end{array}$ & WT $(\mathrm{Kw})$ & $D G(k W)$ & $\begin{array}{l}\text { Battery } \\
\text { (Units) }\end{array}$ & $\begin{array}{l}\text { Conv } \\
(\mathrm{kW})\end{array}$ & Dispatch & $\operatorname{COE}(\$)$ & $\mathrm{NPC}(\$)$ & $\begin{array}{c}\text { Operating } \\
\operatorname{Cos}(\$)\end{array}$ & $\begin{array}{l}\text { Initial } \\
\text { Capital }\end{array}$ & $\begin{array}{c}\text { Ren Frac } \\
(\%)\end{array}$ \\
\hline$\$ 0.92$ & 434.4 & PV & & & Battery & Converter & 210 & 315 & & & 56 & 143 & $\mathrm{CC}$ & $\$ 0.130$ & $2,67,192$ & $\$ 1,660$ & $2,45,653$ & 100 \\
\hline$\$ 0.92$ & 434.4 & $\mathrm{PV}$ & & $D G$ & Battery & Converter & 210 & 315 & & 73 & 56 & 143 & $\mathrm{CC}$ & $\$ 0.144$ & $2,95,078$ & $\$ 1,660$ & $2,73,539$ & 100 \\
\hline$\$ 0.95$ & 434.4 & $\mathrm{PV}$ & WT & & Battery & Converter & 348 & 315 & 1 & & 33 & 80.7 & $\mathrm{CC}$ & $\$ 0.190$ & $3,89,578$ & $\$ 1,185$ & $3,74,263$ & 100 \\
\hline$\$ 0.95$ & 434.4 & PV & WT & $D G$ & Battery & Converter & 348 & 315 & 1 & 73 & 33 & 80.7 & $\mathrm{CC}$ & $\$ 0.204$ & $4,17,464$ & $\$ 1,185$ & $4,02,149$ & 100 \\
\hline
\end{tabular}

Figure 6: Screenshot of simulation for finding optimal design (grid connected)

\subsection{Power Converter}

Name: system converter, manufactured by Generic. Its lifetime is about 25 years. In this paper, the capital cost for a $1 \mathrm{~kW}$ converter is \$120. Replacement cost is \$120 and operation and maintenance cost practically zero.

\subsection{Battery Storage Bank}

The name of the battery bank is EnerStore 50 Agile Flow Battery with a capacity $50 \mathrm{kWh}$, lifetime 30 years. Its efficiency is about $72 \%$. In grid-connected designs, a battery is only used during any fault on the grid to maintain the continuity of supply.

\subsection{Grid}

In grid connected design, a grid is used as a backup power component or excess power absorber. The grid supplies power when there is not enough power from RES to meet the load demand and grid consumes power when excessive power is available.

Considering the availability of renewable energy sources in the considered area, wind and solar energy are used to design the hybrid power system. A battery energy storage is used to support the system in it's off grid mode.

\section{Optimization Results}

Figures 6 and 7 show the optimization results for the hybrid power model without grid connection. For off grid connected system, as shown in Fig. 6, the minimum COE obtained from the result is $\$ 0.130$. In this scenario, the percentage of renewable energy contribution is $100 \%$. In the proposed grid connected model, an optimum number of renewable energy sources is activated and supplies electricity to the load. The total cost of electricity consumption for 25 years for street lights of NIT, Jamshedpur in India is $\$ 314,062$ without the use of hybrid system. 
From figure 7 it is shown that the NPC using hybrid grid system is $\$ 267,192$. The monthly average electricity production from different units using the proposed model is shown in Fig. 9.

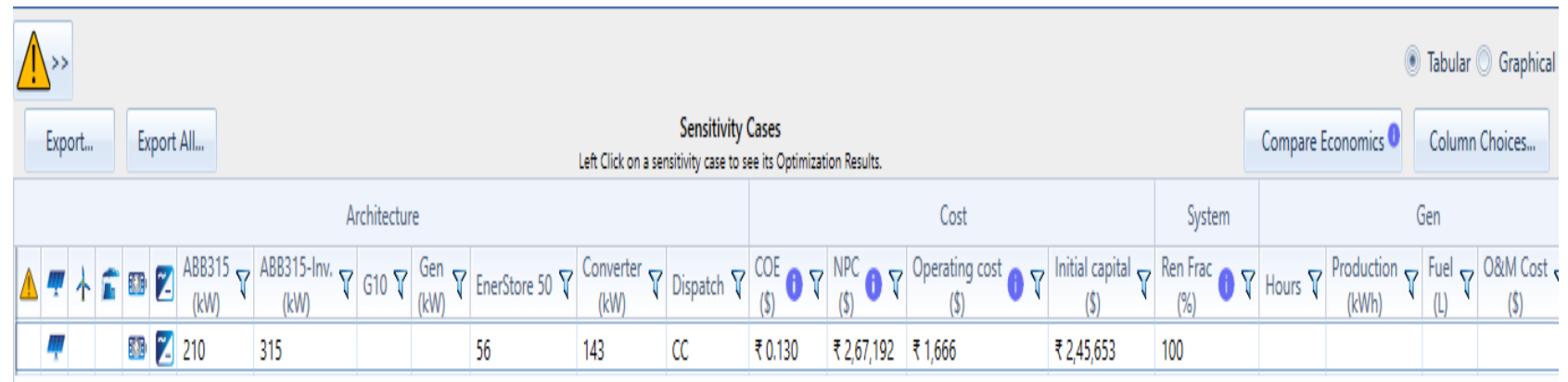

Figure 7: Screenshot of simulation result of off grid power system (PV/Wind/Battery)

\begin{tabular}{|c|c|c|c|c|c|c|c|c|c|c|}
\hline \multicolumn{7}{|l|}{ Simulation Results } & & & & \\
\hline \multirow[t]{3}{*}{ System Architecture: } & \multicolumn{6}{|c|}{ ABB PVS800-315 with Generic PV $(210 \mathrm{~kW} / 315 \mathrm{~kW})$ HOMER Cycle Charging } & Total NPC: & & & 367,19190 \\
\hline & \multicolumn{6}{|c|}{ Enerstore SO Agle flow Battery (S6.0 strings) } & Levelized COE & & & 20.1305 \\
\hline & \multicolumn{6}{|c|}{ System Converter (143 kW) } & Operating Cost & & & $1,666.15$ \\
\hline Cost Summary Cash flow $C$ & \multicolumn{2}{|c|}{ Compare Economics Electrical } & Renewable Penetration : & EnerStore 50 Agile & Flow Batter & ery ABB PVSS00-315 with Generic PV & System Converter & Emissions & & \\
\hline \multicolumn{2}{|l|}{ Production } & kWh/yr or & & Consumption & kWhyr ? & $\%$ & Quantity & kWhyr & $\%$ & \\
\hline \multicolumn{2}{|c|}{ ABB PVS 800 - 315 with Generic PV } & $3,63,398 \quad 100$ & & AC Primary Load & $1,58,421$ & 100 & \multirow{3}{*}{$\begin{array}{l}\text { Excess Electricity } \\
\text { Unmet Electric Load } \\
\text { Capaoty Shortage }\end{array}$} & $1,06,914$ & 29.4 & \\
\hline \multirow[t]{5}{*}{ Total } & & $3,63,398 \quad 100$ & & DC Primary Load & 0 & 0 & & 135 & 0.0850 & \\
\hline & & & & Total & $1,58,421$ & 100 & & 154 & 0.0970 & \\
\hline & & & & & & & \multicolumn{2}{|l|}{ Quantity } & Value & \\
\hline & & & & & & & \multicolumn{2}{|c|}{ Renewable Fraction } & 100 & \\
\hline & & & & & & & \multicolumn{2}{|c|}{ Max. Renew. Penetration } & 708 & \\
\hline
\end{tabular}

Figure 8: Snapshot of the production and consumption scenario.

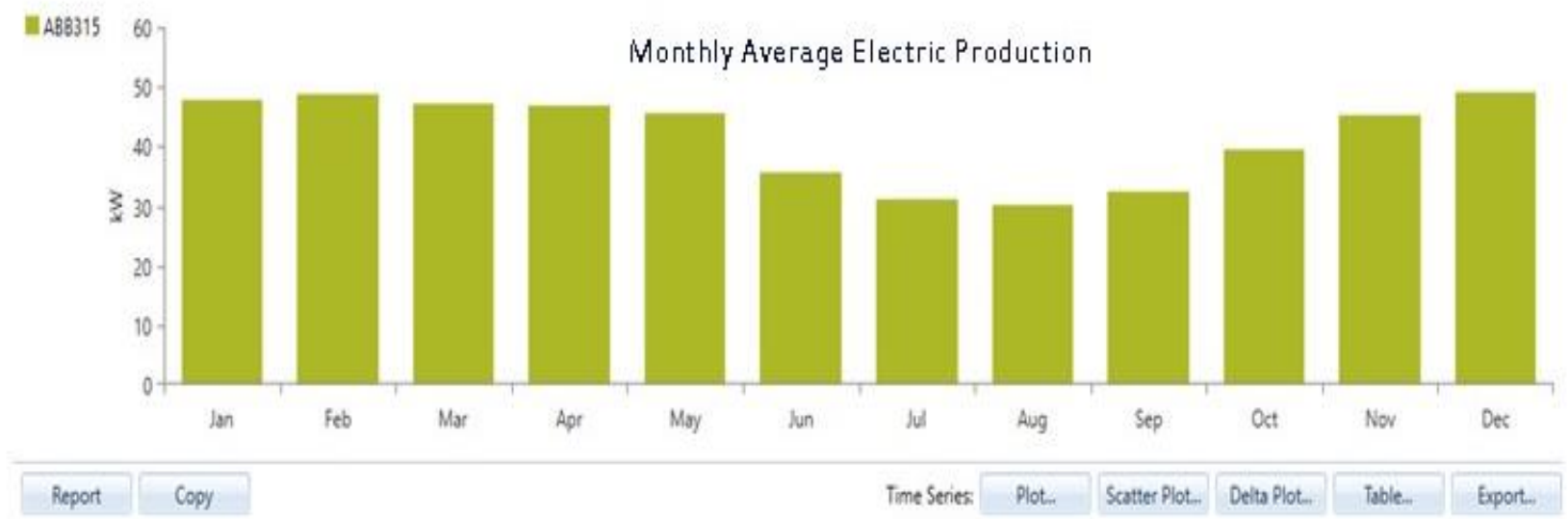

Figure 9: Monthly average electricity production using the proposed model 


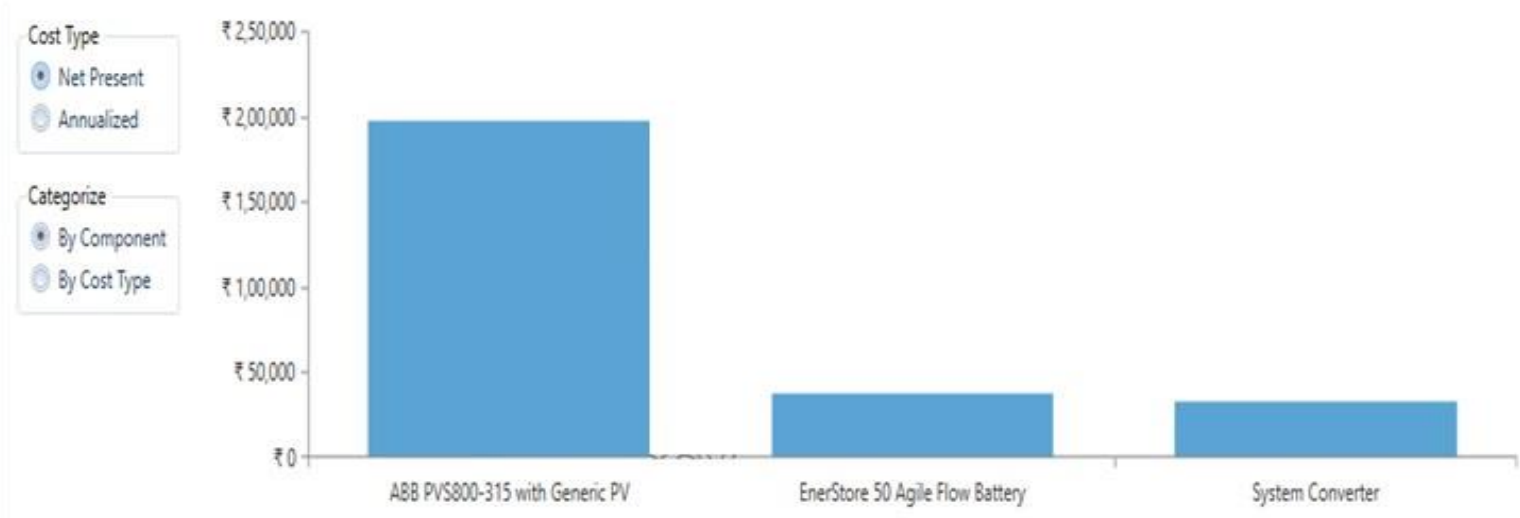

Figure 10: Cost summary by cost type

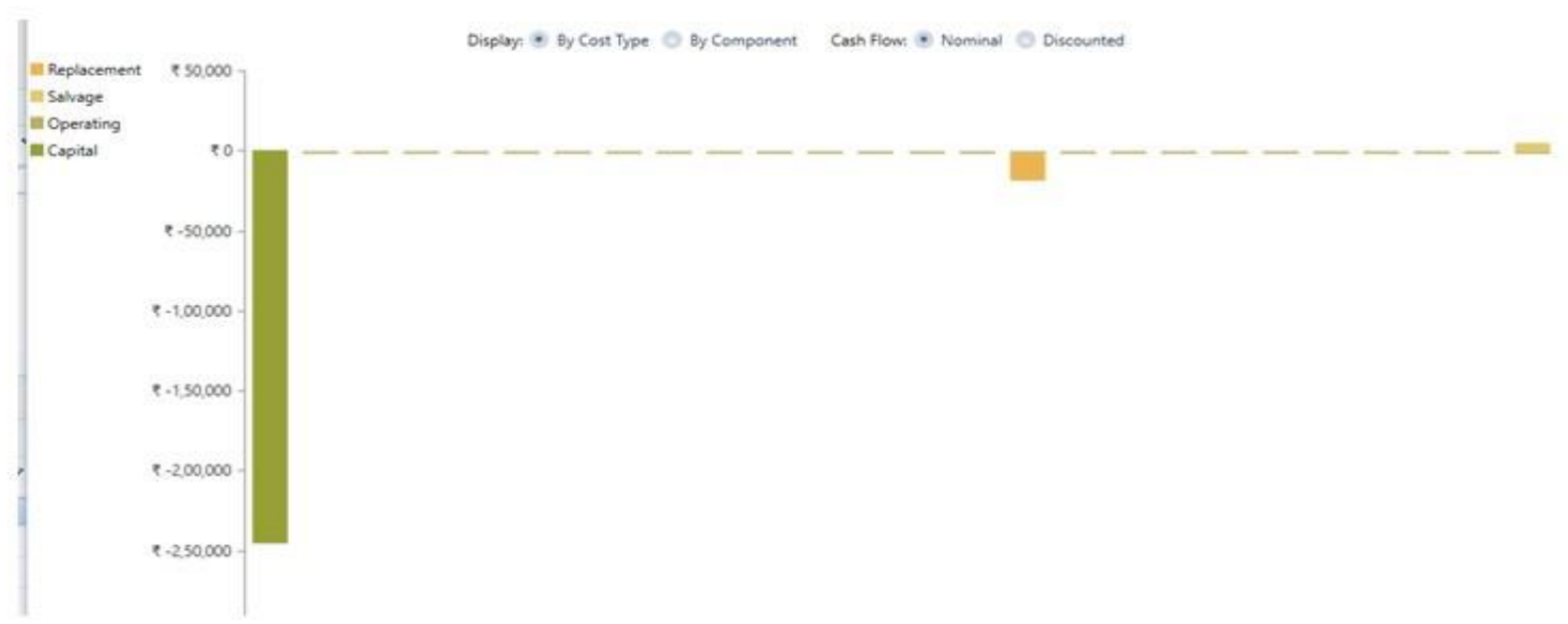

Figure 11: Cash flow summary

\section{Conclusion}

This paper presents a comparative analysis between cost of electricity for street lights in NIT Jamshedpur using solar hybrid system and cost of electricity from conventional sources. We see that electricity production using solar hybrid system is more efficient and economical.

\section{References}

[1] MdShariz Ansari, Sagar Garg, Sagar Kaushik, Shivam Sachdeva. " Solar and Wind Hybrid Energy System for street lighting"

[2] NASA Surface meteorology and solar energy database.

[3] Ahmad Rohani, Kazem Mazlumi, and Hossein Kord, "Modeling of a hybrid power system for economic analysis and environmental impact in HOMER," $18^{\text {th }}$ Iranian conference on Electrical Engineering (ICEE), 819-823, 11-13 May 2010.

[4] www.indiamart.com 
[5] F. Giraud, and Z. M. Salameh, "Steady-state performance of a grid connected rooftop hybrid wind-photovoltaic power system with battery storage," IEEE Trans. on Energy Conversion, vol. 16, no.1, pp. 1-7, 2001.

[6] R. Ramakumar, I. Abouzahr, and K. Ashenayi, "A knowledge-based approach to the design of integrated renewable energy systems," IEEE Trans. on Energy Conversion, , vol. 7, no.4, pp.648659, 1992

[7] R. Chedid, H. Akiki, and S. Rahman, "A Decision Support Technique for the Design of Hybrid Solar-Wind Power Systems," IEEE Trans. on Energy Conversion, vol. 13, no.l, pp.76-83, 1998.

[8] MdNurunnabi, N.K.roy "Grid connected Hybrid Power system design using HOMER"

[9] B. E. Turkay and A. Y. Telli, "Economic analysis of standalone and grid connected hybrid energy systems," International Conference on Electrical and Electronics Engineering, pp.1-34-1-39, 5-8 Nov., 2009.

[10] www.nrel.gov/homer

[11] Getting Started Guide for HOMER Version 3.3.1; 〈https://www.homerenergy. com〉.

[12] H. Rezzouk and A. Mellit, "Feasibility study and sensitivity analysis of a stand-alone photovoltaic-diesel-battery hybrid energy system in the north of Algeria," Renewable and Sustainable Energy Reviews, vol. 43, 1134-1150, 2015.

*Corresponding author.

E-mail address: Kr.manish2695@gmail.com/maheshnagar177@gmail.com/mkpaswan.me@ nitjsr.ac.in /rajeev3278@yahoo.co.in 